\title{
Clinical Profile, Associated Co-morbidities and Risk Factors of Cerebral Palsy in Children in Sohag, Egypt
}

\author{
Montaser M Mohamed ${ }^{1}$ and Rasha A Ali $^{2}$ \\ ${ }^{1}$ Pediatrics Department, ${ }^{2}$ Public Health \& Community Medicine, Faculty of Medicine, \\ Sohag University
}

Received: Feb $2017 \quad$ Accepted: May 2017

\begin{abstract}
Background: Cerebral palsy (CP) is a group of permanent disorders of movement and posture resulting from a non-progressive lesion to an immature brain. Objective: is to identify the prevalent subtypes, associated co-morbidity and risk factors of $\mathrm{CP}$ among children less than 12 years in Sohag, Egypt. Method: a case control study was conducted where 122 cases of CP attending the neuropediatric clinic of Sohag University Hospital were compared to age and sex matched control group (280 normal children) as regard history of prenatal, perinatal and postnatal risk factors of CP. Data related to the subtype and associated co-morbidity were also collected from the studied cases of CP. Results: Among the studied cases of CP, $45 \%$ had quadriplegia, 9.8\% and $6.5 \%$ had hemiplegia and paraplegia respectively. $77.8 \%$ had spastic $\mathrm{CP}$ and $65 \%$ had hypertonia. $65 \%$ of cases had intellectual sub-normality, $29.5 \%$ of cases had epilepsy, $25 \%$ and $15 \%$ of cases had visual and hearing impairment respectively and $23.3 \%$ of the cases suffered from contracture. History of perinatal asphyxia and post natal encephalitis were the only detected significant risk factors for $\mathrm{CP}$. Conclusion: The most common type of $\mathrm{CP}$ detected in our locality was severe spastic (hypertonic) quadriplegia level IV, these findings were attributed to the most common risk factors of CP in our locality which were hypoxic-ischemic encephalopathy and CNS infections. Appropriate screening and management of co-morbidities especially vision, hearing and seizures, improve the overall prognosis in cases of $\mathrm{CP}$.
\end{abstract}

Key words: Cerebral Palsy, Risk factors, Neuropediatric.

Corresponding author : Rasha A. Ali_Email: rashaali815@yahoo.com

\section{Introduction}

Cerebral palsy (CP) indicates a group of permanent disorders that affect movement and posture and result from a non- progressive lesion to an immature brain. ${ }^{1} \mathrm{CP}$ is not considered a disease entity but it is a clinical description of children who suffer brain lesion acquired during the prenatal, natal or early postnatal period. ${ }^{2} \mathrm{CP}$ is considered the most common and devastating motor disability in childhood where according to $\mathrm{CDC}$, a prevalence of $\mathrm{CP}$ ranging from 1.5 to more than 4 per 1,000 live births or children of a defined age range was reported. ${ }^{3}$ In Egypt a prevalence rate of $2.04 / 1000$ of living births was documented. ${ }^{4}$ The burden of CP that includes direct and indirect economic cost is huge. However it is not accurately estimated in Egypt due to lack of relevant medical records and registries of the total number of affected children. Based on CDC report, apart from the indirect economic cost, medical cost of children with $\mathrm{CP}$ alone and those with both $\mathrm{CP}$ and intellectual disability were 10 and 26 times that of normal children respectively. ${ }^{5} \mathrm{CP}$ is considered a heterogeneous condition where heterogenicity is reflected in presence of multiple causes and risk factors, many clinical types, various associated problems such as intellectual disability, hearing and visual impairment and epilepsy for example. ${ }^{6} \mathrm{CP}$ is also 
related to Public health issues like quality of prenatal and natal health care services. This assumption is based on the fact that $\mathrm{CP}$ is associated with several prenatal, natal and postnatal risk factors where premature birth, low birth weight, birth asphyxia, kernictrus and neonatal infection are the most common reported etiologies. ${ }^{7}$

The aim of this study is to identify the prevalent subtypes, associated comorbidity and risk factors of $\mathrm{CP}$ among children less than 12 years in Sohag, Egypt.

\section{Method:}

Study Design: This is a case control study where confirmed cases of CP less than 12 years of age were compared to age and sex matched control group of normal children as regard the presence of potential risk factors. Setting: The study was carried out in the neuropediatric and general pediatric clinics of Sohag University hospital along a duration of six months extending from June $1^{\text {st }}$ to December 30 2016. Participants: Cases were any child less than 12 years old with previously confirmed diagnosis of $\mathrm{CP}$ according to the international classification of diseases [8]. These children were under routine follow up in the Neuropediatric clinic of Sohag University Hospital. Exclusion criteria included isolated movement disorders with no other evidence of $\mathrm{CP}$, metabolic disorders, and incomplete or uncertain past history.

All cases of CP who attended the Neuropediatric clinic along six months duration were included in the current study, accordingly, 122 children having cerebral palsy were enrolled in the study after obtaining consents from their parents.

The control group included 218 normal children (completely neurologically and physically normal) who were referred to the general pediatric clinic for diagnosis and treatment of common childhood infection such as diarrhea or common cold. Both case and control groups were matched as regard age and sex.

Study instrument: After approval from parents of selected children (both case and control groups) on participating in the study, data were collected by the researcher. A specifically prepared data sheet that included age, sex and residence data in addition to data about the potential risk factors (history of pregnancy complication( as fever and pre- eclampsia, fetal risk factors as prematurity, hypoxia, low birth weight, meningitis, encephalitis and jaundice (kernictrus)) was completed.

Medical and neurological evaluation of the cases of CP was performed for 1collection of data about the presence of associated health problems like contracture and joint deformity, malnutrition, intellectual disability, lung diseases, seizures and other neurological problems( movement- speech- hearing and visual impairment). 2- detection of the most common type of $\mathrm{CP}$ according to different classification systems to help physicians in choosing the best treatment options. These classification include 1severity (mild CP; child who can move without assistance with no limitation of daily activities, moderate $\mathrm{CP}$; child who needs braces and medications to practice his daily activities, sever CP; child requires a wheel chair and faces significant challenges to perform his daily activities and No $\mathrm{CP}$; a child that has signs of CP ( motor impairment) but the impairment was acquired after completion of the brain development such as traumatic brain injury or encephalopathy), 2- topographic classification; means location of motor impairment such as hemiplegic, diplegic or tetraplegic $\mathrm{CP}, 3-$ Motor function classification; spastic (pyramidal), non spastic (extrapyramidal) or mixed (some limbs are affected by spasticity and others by athetosis), 4- classification based on muscle tone; whether 
hypertonia or hypotonia and 5classification based on Gross Motor Function Classification System (GMFCS); level of functional mobility impairment as it is consists of five levels ranging from level I which means minimal mobility dysfunction to level $\mathrm{V}$ which indicates child who is totally dependent and needs help to move.

\section{Statistical analysis:}

Statistical Package for the Social Science (SPSS) program( version 20) was used for grouping, tabulation and statistical analysis of the data. Sample characteristics were summarized using the mean and the standard deviation (SD) for continuous variables and percentage for categorical variables. Chi square test was used to estimate the difference and $\mathrm{P}$ value below 0.05 was considered significant. Univariate and logistic regression analyses were used to evaluate relation between risk factors and $\mathrm{CP}$.

\section{Ethical consideration:}

Approval of conducting the research was obtained from Scientific Research Ethical Committee of the faculty of Medicine, Sohag University before starting data collection. During data collection stage, we obtained informed consents from parents of the studied children (both cases and controls) which included explanation of the purpose of the study to them and ensuring strict confidentiality and anonymity of all the collected data.

\section{Results:}

The mean age of the studied cases of CP was four years with SD of 2.9 years. $79.2 \%$ (89 children) were boys while $27.1 \%$ (33 children) were girls. Male: female ratio was 2.9: 1. consanguinity was positive among parents of $37.3 \%$ of the cases $22.2 \%$ of the studied children had positive family history of cerebral palsy (Table1).

As regard severity of CP $45.8 \%$ had severe $\mathrm{CP}, 27.8 \%$ and $24.8 \%$ had mild
Table (1): Socio demographic data of the studied cases of $C P$

\begin{tabular}{lr}
\multicolumn{1}{c}{ Variable } & \multicolumn{1}{c}{$\begin{array}{c}\text { Statistics } \\
(\mathbf{N}=122) \\
\text { N (\%) }\end{array}$} \\
\hline Age in years & \\
$\quad$ Mean (SD) & $4(2.9)$ \\
$\quad$ Range & $1-12$ \\
Sex & \\
- Males & $89(72.9)$ \\
- Females & $33(27.1)$ \\
+ ve Family history & $27(22.2)$ \\
\hline
\end{tabular}

and moderate CP respectively. As regard type of paralysis, $45 \%$ had quadriplegia, $9.8 \%$ had hemiplegia and $6.5 \%$ had paraplegia. Most of the studied cases of $\mathrm{CP}$ had spastic $\mathrm{CP}$ and hypertonia (77.8\% and 65\% respectively) (Table2).

Figure (1) displays the associated comorbidities detected among the studied cases of $\mathrm{CP}$; the most prevalent comorbidity was intellectual sub-normality in $65 \%$ of cases followed by epilepsy in $29.5 \%$ of cases. $25 \%$ and $15 \%$ of cases had visual and hearing impairment respectively. $23.3 \%$ of the studied cases of $\mathrm{CP}$ suffered from contracture while $17.2 \%$ and $10 \%$ of them had malnutrition and joint deformity respectively.

Table (3) shows distribution of the cases and controls as regard the studied risk factors. History of fever during pregnancy was positive in one case only vs none in control and this was the case also concerning history of pre-eclampsia $(\mathrm{p}>0.05)$. Concerning natal risk factors, history of hypoxia was significantly more common among cases compared to controls (30 (24.5\%) cases VS 6 (2.7\%) controls) ( $\mathrm{P}<0.000)$. As regard post natal risk factors the only detected significant factor was encephalitis in 6 $(4.9 \%)$ cases compared to none in control $(\mathrm{p}=0.01)$.

As regard results of logistic regression analysis, the only significant risk factor was history of cyanosis at birth $(\mathrm{OR}=$ 12.3 with $95 \%$ CI of $4.9-31.2$ ) presented in table (4). 
Discussion:

Table (2): classification of the studied cases of $\mathbf{C P}$

\begin{tabular}{l|r|}
\hline \multicolumn{1}{|c|}{ Classification } & $\begin{array}{c}\text { Summary } \\
\text { statistics } \\
\text { ( N= 122 ) } \\
\text { N (\%) }\end{array}$ \\
\hline Severity : & \\
- Mild & $30(24.8)$ \\
- Moderate & $34(27.8)$ \\
- Severe & $56(45.8)$ \\
- No C.P* & $2(1.6 \%)$ \\
\hline Topographic & \\
classification: & \\
- Paresis & $37(30)$ \\
- Paralysis & $85(70)$ \\
- Monoplegia & $7(5.7)$ \\
- Diplegia & $3(2.5)$ \\
- Hemiplegia & $12(9.8)$ \\
- Paraplegia & $8(6.5)$ \\
- Quadriplegia & $55(45)$ \\
\hline Motor Function & \\
classification: & \\
- Spastic & \\
- Non spastic & $95(77.8)$ \\
- Mixed & $17(14)$ \\
\hline Classification based on & $10(8.2)$ \\
muscle tone: & \\
- Hypertonia & \\
- Hypotonia & $80(65.5)$ \\
\hline Classification based on & $42(34.5)$ \\
GMFCS & \\
- Level I & \\
- Level I & $20(16.4)$ \\
- Level III & $15(12.3)$ \\
- Level IV & $15(12.3)$ \\
- Level V & $55(45)$ \\
\hline
\end{tabular}


Table (3): Distribution of the cases and controls as regard the studied risk factors of CP

Several classification systems for CP that determine the type and form of motor impairment of the child are available. Although classification of $\mathrm{CP}$ is complicated by presence of different clinical presentations and many degrees of activity limitation but knowing the location, location and severity of $\mathrm{CP}$ helps to coordinate care and lines of treatment needed. 9,11 Professionals concerned with $\mathrm{CP}$ view the condition from different points; an orthopedic surgeon needs determination of the affected limbs and the extent of impairment in order to decide treatment. While the cause and the type of brain injury is what matter to Neurosurgeons. Parents or caregivers may need to know the severity level classification - mild, moderate or severe - in order to better understand the seriousness of the child's disability. Furthermore, government agencies are more concerned with classification systems that help them

For all previous important reasons in our

Table (4) logistic regression analysis of potential risk factors of $\mathrm{CP}$

\begin{tabular}{lcc}
\hline Characteristics & $\begin{array}{c}\text { OR } \\
(\mathbf{9 5 \%} \mathbf{C I})\end{array}$ & $\begin{array}{c}\text { P - } \\
\text { value }\end{array}$ \\
\hline $\begin{array}{l}\text { Fever during } \\
\text { pregnancy }\end{array}$ & 0.4 & 1.0 \\
Pre eclampsia & $(0.00-1.9)$ & \\
& 0.4 & 1.0 \\
Premature birth & 3.5 & \\
$\begin{array}{l}\text { Cyanosis at } \\
\text { birth }\end{array}$ & $\begin{array}{c}1.09-11.7) \\
\mathbf{1 2 . 6}\end{array}$ & 0.5 \\
$\begin{array}{l}\text { Low birth } \\
\text { weight }\end{array}$ & $\begin{array}{c}\mathbf{4 . 9}-\mathbf{3 1 . 2}) \\
0.6\end{array}$ & $\mathbf{0 . 0 0 1}$ \\
Jaundice & $(0.2-1.8)$ & 0.4 \\
(kernitrus) & 0.4 & 0.5 \\
Meningitis & $(0.2-1.2)$ & \\
Encephalitis & $\begin{array}{c}7.4 \\
(0.7-72.9)\end{array}$ & 0.08 \\
\hline
\end{tabular}

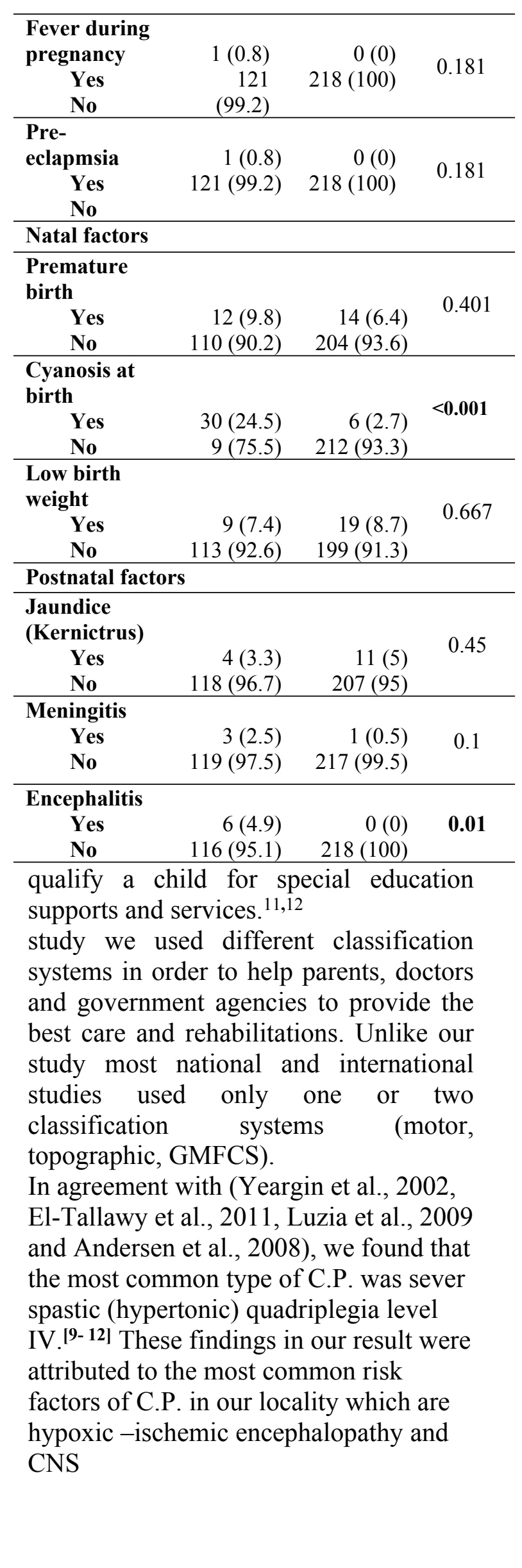




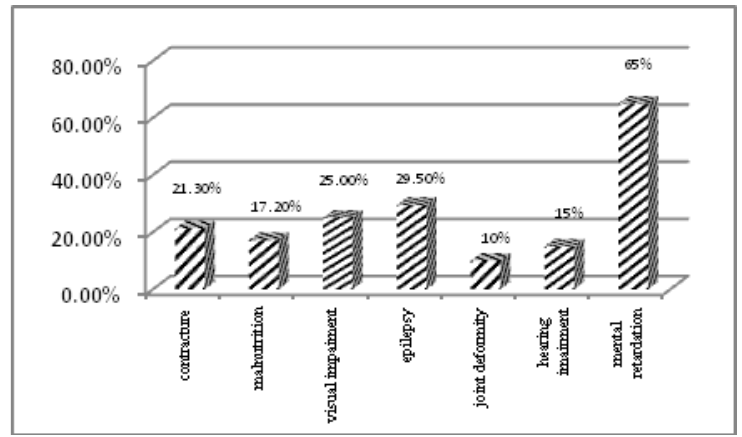

Figure (1) Associated co-morbidities among the studied cases of $\mathrm{CP}$ infections. The most prevalent comorbidity detected among cases of $\mathrm{CP}$ was intellectual sub-normality in $65 \%$ of cases followed by epilepsy in $29.5 \%$ of cases. $25 \%$ and $15 \%$ of cases suffered from visual and hearing impairment respectively. $23.3 \%$ of the studied cases of CP suffered from contracture while $17.2 \%$ and $10 \%$ of them had malnutrition and joint deformity respectively. These findings are comparable to (Hou et al., 2010, Gowda et al., 2015 and Sharma et al., 1999). ${ }^{13-15}$ however percentage of malnutrition was less than that reported in these studies. The underlying causes of the CP still under debate and vary from medical mismanagement at birth to multifactor process which includes also genetic factors. ${ }^{16}$ As regard the studied potential risk factors no significant association was found between pregnancy complications including history of fever or pre-eclampsia and CP. These findings are inconsistent with (WU et al., 2006, Inaloo et al., 2016 and O'Callaghan et al., 2011) as regard fever during pregnancy. $7,16,17$ While Brookfield et al., 2016 agree with us as regard fever ${ }^{[18]}$. These findings in our result may be attributed to improvement of antenatal care including monitoring blood pressure, urine analysis and vaccination which are provided routinely for every pregnant mother.

We considered cyanosis at birth the presentation of birth hypoxia, regardless of whether true hypoxic-ischemia was present. This is because finding cyanosis at birth may denotes presence of hypoxic-ischemia in a neonates with encephalopathy. Thus, if we consider cyanosis at birth as clinical symptoms of birth hypoxia we can conclude that birth hypoxia" was a strong predictor of CP in our study population. Besides, results of logistic regression analysis indicated this significant association (OR 12.3 with 95\% CI of 4.4-34). These findings are consistent with M.Gladstone , $2010^{19}$ and many studies in Iran (Inaloo et al., 2016, Daher et al., 2014, Hermansen et al., 2006 and Soleimani et al., 2009) ${ }^{[16]}$, [20-22]. On the other hand, these findings are inconsistent with El-Tallawy et al., $2014 .^{23}$ In agreement with M.Gladstone, 2010 [19] we found no significant association between preterm birth and CP although these findings are inconsistent with (WU et al., 2006, Inaloo et al., 2016 and El-Tallawy et al., 2014). 7,16,23 In agreement with Inaloo et al., $2016{ }^{[16]}$ we found no significant association between low birth weight and $\mathrm{CP}$. These findings disagree with (WU et al., 2006, 2016, Daher et al., 2014 and El-Tallawy et al., 2014 ). ${ }^{7,20,23}$ These finding are explained by the fact that there was a great advances in different neonatal unites including surfactant therapy and different ventilation modes especially in university hospital.

As regard history of post natal infections, we found significant association between $\mathrm{CP}$ and encephalitis only while no significant association was found as regard meningitis. These results are consistent with (M.Gladstone, 2010 and Banskota et al., 2015). ${ }^{19}, 24$ In contrast to Brookfield et al., 2016, we found no significant association between kernictrus and CP. ${ }^{18}$ Jaundice which is caused by excessive bilirubin in the blood, that is filtered by the liver, needs time to get rid of as the neonatal liver starts doing this within days after birth. So it is common for infants to have jaundice for a few days after birth that is in most cases, successfully treated with phototherapy with no permanent health 
effects. Thanks to major advance in neonatal and postnatal care including anti $\mathrm{D}$ therapy, kernictrus as a result of $\mathrm{Rh}$ and $\mathrm{ABO}$ incompatibility became rare nowadays.

\section{Conclusion:}

The most common type of CP detected was sever spastic (hypertonic) quadriplegia level IV indicating high frequency of severe brain insult affecting neonates in our locality. This go in line with our finding that perinatal asphyxia and postnatal encephalitis were the most important risk factors of CP. In addition, numerous Co-morbidities were observed among these cases, indicating necessity of appropriate screening and management of co-morbidities especially vision, hearing, seizures, and nutrition to improve the overall prognosis in cases of CP.

\section{Limitation of the study:}

The most important limitation faced in the current study was depending on recall history concerning the potential risk factors due to absence of relevant medical records.

\section{References:}

1. Rosenbaum P, Paneth N, Leviton A, Goldstein M, Bax M, Damiano D, et al. A report: the definition and classification of cerebral palsy April 2006. Dev Med Child Neurol Suppl 2007; 109: 8-14.

2. McIntyre S, Blair E, Badawi $\mathrm{N}$, Keogh J, Nelson K. Antecedents of cerebral palsy and perinatal death in term and late preterm singletons. Obstet Gynecol 2013;122:869-77

3. Oskoui M, Coutinho F, Dykeman J, Jette E, Pringsheim T. An update on the prevalence of cerebral palsy: a systematic review and metaanalysis. Dev Med Child Neurol 2013;55: 509-19.
4. El-Tallawy
HN1, Farghaly
WM, Shehata GA, Metwally NA, Rageh

TA, Abo-Elfetoh N. Epidemiology of cerebral palsy in El-Kharga District-New Valley (Egypt). . Brain Dev. 2011;33(5):406-11.

5. Kancherla V1, Amendah DD, Grosse SD, Yeargin-Allsopp M, Van Naarden Braun K. Medical expenditures attributable to cerebral palsy and intellectual disability among Medicaidenrolled children. Res Dev Disabil. 2012;33(3):832-40

6. O'Callaghan ME, MacLennan AH, Gibson CS, et al. Epidemiologic associations with cerebral palsy. Obstet Gynecol 2011;118: 576-82.

7. Wu YW, Croen LA, Shah SJ, Newman TB, Najjar DV. Cerebral palsy in a term population: risk factors and neuroimaging findings. Pediatrics 2006;118:690-7.

8. World Health Organization (2005) International Classification of Functioning, Disability and Health (ICF). Geneva: World Health Organization.

9. Yeargin-Allsopp M, Van Naarden Braun K, Doernberg NS, Benedict RE, Kirby RS, Durkin MS. Prevalence of cerebral palsy in 8-year-old children in three areas of the United States in 2002: a multisite collaboration. Pediatrics. 2008;121(3):547-54.

10. El-Tallawy HN, Farghaly WM, Shehata GA, et al: Epidemiology of cerebral palsy in El-Kharga District-New Valley (Egypt). Brain\& Development. 2011;33(5):406-11.

11. Luzia Iara PfeiferI, Daniela Baleroni Rodrigues SilvaI, Carolina Araújo Rodrigues FunayamaII, Jair Lício SantosI. Classification of cerebral palsy: association between gender, age, motor type, topography and Gross Motor Function. Arq. Neuro-Psiquiatr. 2009; 67(4) 
12. Andersen GL1, Irgens LM, Haagaas I, Skranes JS, Meberg AE, Vik T. Cerebral palsy in Norway: prevalence, subtypes and severity. Eur J Paediatr Neurol. 2008;12(1):4-13.

13. Hou M1, Sun DR, Shan RB, Wang $\mathrm{K}, \mathrm{Yu} \quad \mathrm{R}$, Zhao JH, Jiang YP. Comorbidities in patients with cerebral palsy and their relationship with neurologic subtypes and Gross Motor Function Classification System levels. Zhonghua Er Ke Za Zhi. 2010;48(5):3514.

14. Gowda VK1, Kumar A2, Shivappa SK2, Srikanteswara

PK3, Shivananda2, Mahadeviah

MS2, Govindraj M2, Ramaswamy P2. Clinical profile, predisposing factors, and associated co-morbidities of children with cerebral palsy in South India. J Pediatr Neurosci. 2015;10(2):108-13.

15. Sharma P,Sharma U, Kabra A. Cerebral palsy - Clinical profile and predisposing factors. Indian Pediatr. 1999;36:1038-42.

16. Inaloo $\mathrm{S}$, Katibeh $\mathrm{P}$, Ghasemof $\mathrm{M}$. Cerebral Palsy in 1-12 Year Old Children in Southern Iran. Iran J Child Neurol.Winter 2016; 10(1):35-41.

17. O'Callaghan ME, MacLennan AH, Gibson CS, et al. Epidemiologic associations with cerebral palsy. Obstet Gynecol 2011;118: 576-82.

18. Brookfield KF1, Osmundson SS2, Caughey AB1, Snowden JM1. Does Infection During Pregnancy Outside of the Time of Delivery Increase the Risk of Cerebral Palsy? Am J Perinatol.2016

19. M.Gladstone. A review of the incidence and prevalence, types and aetiology of childhood cerebral palsy in resource-poor settings. Annals of Tropical Paediatrics 2010; 30:181-196
20. Daher S, El-Khairy L.. Association of cerebral palsy with consanguineous parents and other risk factors in a Palestinian population. East Mediterr Health J. 2014 ;20(7):459-68.

21. Hermansen MC, Hermansen MG. Perinatal infections and cerebral palsy. Clin Perinatol 2006;33:315-33.

22. Soleimani F, Vameghi R, Hemmati S, Salman Roghani R. Perinatal and neonatal risk factors for neurodevelopmental outcome in infants in Karaj. Arch Iranian Med 2009;12:135-9.

23. El-Tallawy, H. N. et al. Cerebral palsy in Al-Quseir City, Egypt: prevalence, subtypes, and risk factors. Neuropsychiatr. Dis. Treat. 2014; 10:1267-72

24. Banskota B1, Shrestha S1, Rajbhandari T1, Banskota AK1, Spiegel DA1. A Snapshot of 1001 Children Presenting with Cerebral Palsy to a Children's Disability Hospital. J Nepal Health Res Counc. 2015;13(29):31-7. 